\title{
A Computer-Based Study of the Yaw/Roll Stability of Heavy Trucks Characterized by High Centers of Gravity
}

\author{
Charles C. MacAdam \\ The University of Michigan \\ Transportation Research Institute
}

\section{ABSTRACT}

A class of heavy truck vehicles, characterized primarily by high centers of gravity, was studied using analysis and computer simulation to identify and understand the relationship between directional and roll stability of such vehicles during steady turning maneuvers. Findings of the computer-based study suggest: (1) directional instability (yaw divergence) is possible for such vehicles during steady turning while operating at elevated speeds on horizontal road surfaces, (2) yaw divergence will lead to rollover in the absence of corrective steering action and/or reduced speed, and (3) the primary mechanism responsible for precipitating yaw divergent behavior in such vehicles is the nonlinear sensitivity of truck tire cornering stiffness to vertical load acting in combination with typical heavy truck fore/aft roll stiffness distributions. In addition, the influences of roadway superelevation and driver steering control as contributors to vehicle stabilization are examined and discussed.

THE PRINCIPAL FOCUS of this paper is to explain and illustrate, through use of simplified analysis and computer simulation, the relationship between directional (yaw) stability and roll stability of heavy trucks with high centers of gravity. The emphasis here, as will become clear, is not directed toward roll-related dynamics and identification of roll thresholds for such vehicles, but instead, toward an explanation of yaw divergence, per se, and its potential for precipitating roll instability (rollover) at highway speeds and low levels of lateral acceleration.

Yaw instability, or yaw divergence as it is frequently referred to, manifests itself as the tendency of a vehicle's heading to diverge, or increasingly point away, from the direction of travel. Terms such as "spin-out" for motor cars, and "jackknife" for articulated vehicles, are commonly used to describe this general behavior. Although yaw divergence phenomena are frequently encountered with vehicles during braking maneuvers, the concern and attention here is directed only at the occurrence of yaw divergence during steady turning at constant forward velocity. As will be shown, the principal mechanism responsible for the onset of yaw divergence in heavy trucks is the combination of: (1) cornering stiffness sensitivity of truck tires to vertical load, (2) fore/aft roll stiffness distribution, and (3) high center of gravity heights. Moderate reductions in any one of the aforementioned mechanisms can have a significant effect in improving the directional stability of such vehicles at elevated speeds. The previous experimental and computer simulation work of Ervin, et al. $(1,2) *$ in studying the yaw stability of tractor-semitrailer vehicles during cornering has shown that tractor yaw instability (jackknifing) can occur well below the rollover threshold for certain vehicles. Modification of such vehicles' fore/ aft roll stiffness distribution was shown experimental1y, and supported by computer simulation results, to eliminate the occurrence of tractor yaw divergence. In addition, other vehicle parameters were systematically examined to evaluate their influence in increasing or decreasing the potential for tractor yaw instability during steady turning.

A significant analytical by-product of the work of Ervin, et a1., was the introduction of a graphical plot herein termed the "non-linear handling diagram." The prior analytical work of Pacjecka (3) in defining a so-called "handling diagram" and its subsequent adaptation by Ervin, et al., in the above study to the non-linear steady turning response of tractor-semitrailers, has led to the use of the analogous "non-linear handling diagram" for analyzing the directional stability of such vehicles.

*Numbers in parentheses designate references at end of paper. 
A recent paper by Segel and Ervin (4) concerned with the influence of tire factors on truck stability, and based largely upon the results of a previous research project (5), concluded that: (1) certain heavy truck vehicles were quite capable of exhibiting yaw divergent behavior during steady turning at a severity level far below that needed to achieve limit response of passenger cars, and (2) that a marked degradation in directional controllability can accrue well in advance of the maneuver severity required to roll over the vehicle. Furthermore, Segel and Ervin concluded that the fore/aft roll stiffness distribution was the primary mechanism serving to aggravate the yaw stability of the heavy truck, and that the commercial vehicle tire was seen to exhibit certain shear-force-related. properties which cause trucks to respond differently to parametric variations than typical passenger cars.

The above summary suggests a strong relationship between the above work and that presented in this paper. The principal differences between the two lie with: (1) examination of two different and distinct heavy truck tire properties, and (2) the level of severity of the steady turning maneuver. The above study examined the development of yaw divergent behavior as the cornering limit of the vehicle was approached (i.e., within the sub-limit maneuvering regime) and demonstrated dependence of such behavior upon the non-linear shear force properties of the tires. In contrast, this paper examines the variation of tire cornering stiffness with vertical load--a low level, linear regime tire property--and demonstrates how it, acting in concert with load transfer mechanisms, also can precipitate yaw divergence, but at levels of lateral acceleration well below those identified in the above study. As will be seen, the prerequisites for the latter behavior to occur are: (1) as in the above study, significant fore/aft roll distribution margins must be present, and (2) in contrast with the above study, the vehicle must possess a relatively high center of gravity.

A number of investigators have studied the static and steady turning roll stability of articulated vehicles $(6,7,8,9)$. More recently, the work of Mallikarjunarao and Ervin $(10,11)$, in comprehensively examining the individual. mechanical elements that contribute to the rollover event, has led to a good understanding and explanation of the articulated vehicle rollover process. Since most of these findings are seen as equally applicable to the straight truck vehicle during steady turning, this paper simply accepts, and elects not to reiterate herein, those same results for the straight truck vehicle. Therefore, the view adopted here, with regard to heavy truck roll stability under steady turning conditions, is that a rollover threshold exists and is expressible in terms of a lateral acceleration level (e.g., g-units) above which the vehicle rolls over, below which it does not. The rollover event, whether precipitated by yaw divergence at higher speeds or encountered without yaw divergence at lower speeds, is viewed as defining the absolute or maximum possible maneuvering regime. The results of computer simulation runs encountering rollover serve to define the absolute maneuvering range, or rollover threshold.

To summarize, previous experimental and analytical research that has addressed the yaw stability issue in commercial vehicles has focused largely upon the development of yaw divergence within the sub-limit maneuvering range. Furthermore, the vehicles examined possessed center of gravity heights that would be classified as moderate. In contrast, the computer-based results presented in this paper focus on the development of yaw divergence and/ or roll instability for trucks possessing high centers of gravity, operating at low levels of lateral acceleration. The principal mechanism responsible for such behavior is shown to be the non-linear variation of truck tire cornering stiffness with vertical load, acting in conjunction with typical, heavy truck fore/aft roll stiffness distributions.

The paper begins with a brief discussion of yaw/roll stability concepts, followed by results of a simplified analysis that assumes typical truck tire cornering stiffness variation with vertical load. Results from a comprehensive computer simulation, which represents the vehicle dynamical behavior in greater detail, are then presented, showing essential qualitative agreement with the results of the preceding simplified analysis. Finally, the topic of closed-loop driver control of yaw divergent vehicles, as represented by a computer model, is introduced and discussed.

\section{YAW/ROLL STABILITY}

As indicated in the introduction, a principal objective of this paper is directed toward achieving a better understanding of how yaw divergence can occur for heavy trucks and its related role as a precipitant of roll instability. That is, the "decoupling" or separate treatment of roll stability and yaw stability that is often appropriate for motor cars and many commercial vehicles is not generally possible with the class of high c.g. heavy truck vehicles being examined here. Yaw divergence in such heavy trucks inevitably leads to rollover, unless the tire/road friction coupling is less than the relatively low rollover threshold of these vehicles. Even though passenger cars and certain tractor-semitrailers can frequently exhibit yaw divergent behavior ("spin outs" and "jackknives") on high friction surfaces without experiencing rollover as well, the high c.g. truck vehicle, in general, cannot. The development of ever increasing sideslip during yaw instability precipitates a corresponding increase in lateral acceleration which very quickly leads to an unstable roll 
response. In fact, many of the same physical mechanisms that define, to first order, the roll stability of such vehicles (e.g., c.g. height, track, fore/aft roll stiffness distribution) also play an important role in defining, with tire force vertical load sensitivity, the yaw stability of these vehicles.

One way of illustrating the yaw and roll stability relationship is to plot for a given vehicle its yaw divergent or "critical" velocity as a function of lateral acceleration (see Fig. 1 , line A). Also shown on the same plot is a vertical line, $B$, defining the rollover threshold for the given vehicle. The yaw/roll stability regime for this vehicle could then be defined as that velocity/lateral acceleration area lying to the left of the combined curves. attended to by corrective driver steering control and/or reduced speed, is that it will quickly lead to a further increase in a vehicle's lateral acceleration and thereby precipitate rollover.

The yaw/roll stability plot is seen as a convenient means for displaying absolute stability levels for a given vehicle, as well as a means for readily illustrating sensitivities of these stability boundaries to variations in typical vehicle parameters. That is, it provides a method for graphically describing regions of stability/instability in terms of easily understandable quantities--speed and lateral acceleration. The next section of this paper demonstrates how such a plot can be used, in combination with simplified analyses, to

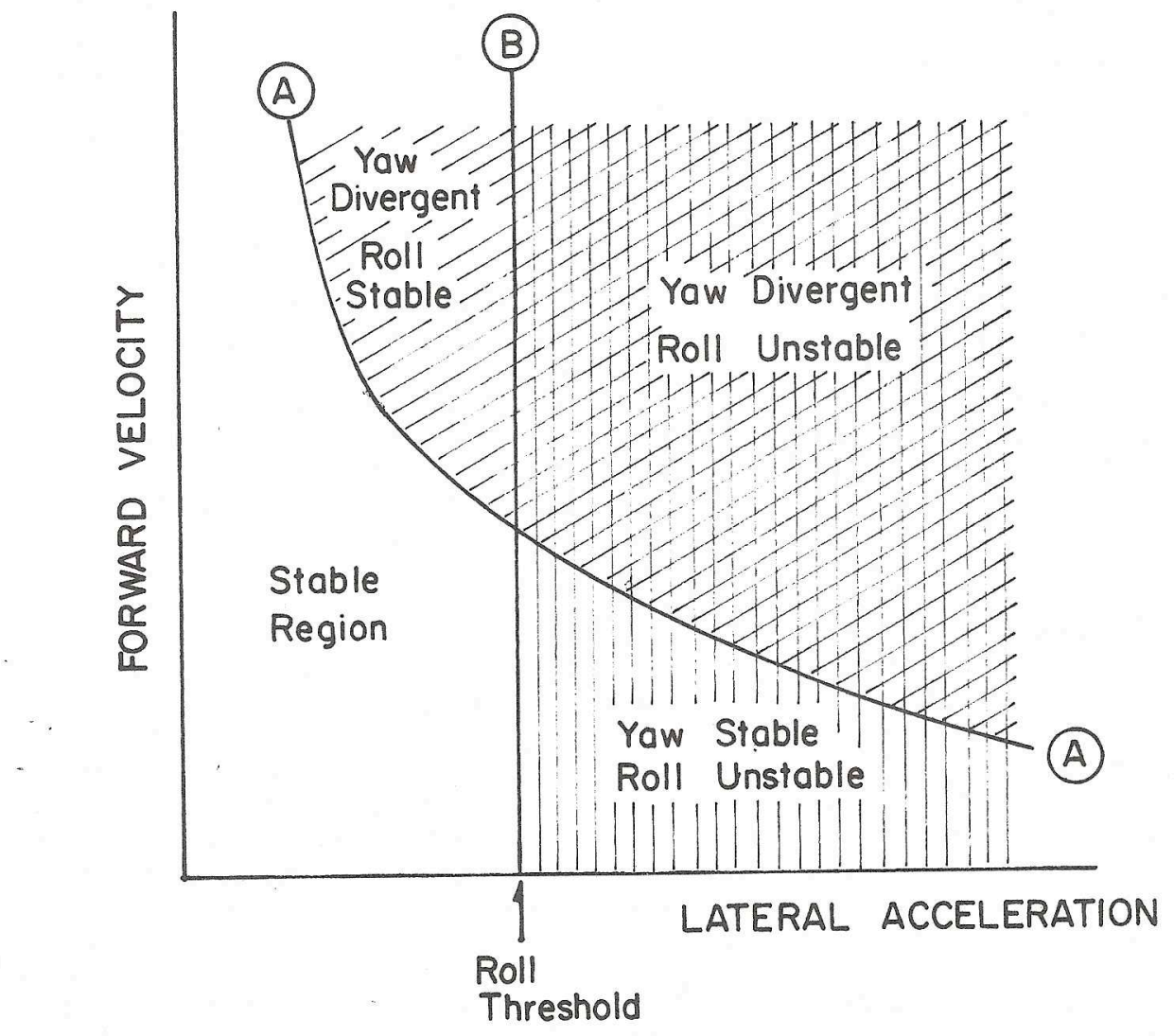

Figure 1. Yaw/roll stability plot.

The yaw/roll stability plot illustrated in Figure 1 is comprised of four distinct regions: (1) the stable region, (2) the yaw-stable/rollunstable region, (3) the yaw-divergent/rol1stable region, and (4) the yaw-divergent/roll unstable region. We see that at low speeds and increasing levels of lateral acceleration (tighter and tighter low-speed turning), the principal stability concern is that of rollover. However, at elevated speeds, as lateral acceleration increases, the principal stability concern is yaw divergence prior to reaching the rollover threshold. The danger of yaw divergence, if not study yaw divergence sensitivity to variations in vehicle parameters. The subsequent section, concerned with more realistic computer simulation predictions, employs such a plot in an absolute sense, to summarize results of computer-based studies, illustrating the interaction/relationship between yaw stability and roll stability for particular vehicles. 


\section{SIMPLIFIED ANALYSIS OF YAW STABILITY}

This section presents results of simplified calculations of yaw stability based on the analysis presented in Appendices A and B. An "average" vehicle representation for the class of high c.g. trucks under study was selected to serve as the baseline calculation. Variations were then made in several of the vehicle parameters in order to reveal sensitivities of yaw stability boundaries to changes in each of the examined parameters. The calculations shown below make use of Equation $(B-5)$ and illustrate the relationship between critical velocity and lateral acceleration operating level. Note that this analysis is conservative in its calculation of yaw divergence, and that its principal aim is to identify sensitivities of yaw stability boundaries to variations in vehicle parameters.

The "average" straight-truck vehicle was defined as having the following baseline properties for the purpose of these simplified calculations:

185-inch wheelbase

18000-1b front axle load

48000-1b rear suspension load shared by three axles

dual tires, 50-inch axle spacing

10:1 front-to-rear roll compliance

80-inch front track

72-inch rear track

$16.5 \times 22$ front tire

$10 \mathrm{~F} \times 20$ rear tire

70-inch total c.g. height above ground and average cornering stiffness sensitivity to vertical load for the tires

identified above

Figure 2 shows a typical result from the simplified analysis entitled "Rear Axle Variations." It describes the sensitivity of the "average" baseline vehicle's yaw stability boundary to the removal or addition of the rearmost axle. Figures 3 and 4 show similar parameter sensitivity results from the simplified analysis. In a more complete portrayal of the vehicle dynamics, as for example in the computer simulation study of the next section, these boundaries will shift further to the left and display a more restrictive operating range of yaw stability. The results of Figures 2-4 indicate that, with respect to yaw stability, this class of vehicles benefits (and suffers) the most from: (a) addition (removal) of rear axles, (b) changes in c.g. height, and (c) variations in rear tire vertical load sensitivity. Greater sharing of lateral load transfer by the front axle also indicates significant improvement in yaw stability.

As indicated, the parameter sensitivity results shown in Figures 2-4 are based upon the simplified analysis contained in Appendices A and $B$. This analysis extends the classical steady turning equation to include the effect of side-to-side load transfer upon the cornering stiffness of each tire. The net result is a more rapid loss of cornering stiffness at the rear of the vehicle, relative to the front, due to typical fore/aft roll stiffness distributions of heavy trucks, as steady turn lateral acceleration levels are increased.

The classical steady turning equation can be written, with the primed quantities denoting dependence upon lateral acceleration, as:

$$
\delta=\frac{\ell_{e}^{\prime}}{R}+K^{\prime} a_{y}
$$

where

$\delta$ is front wheel angle

$R$ is path radius

$a_{y}$ is lateral acceleration

$l_{e}^{\prime}$ is the so-called effective wheelbase for a vehicle with tandem rear suspension, but here, dependent upon lateral acceleration

$\mathrm{K}^{\prime}$ is the classical quantity, $\mathrm{K}$, evaluated with lateral acceleration-dependent cornering stiffnesses. (See Appendix A.)

It is interesting to note that in this analysis the classical understeer gradient, $\mathrm{K}$, which is not dependent upon lateral acceleration, becomes associated with, as shown in Appendices $A$ and $B$, a new quantity of the form

$$
\mathrm{S}=\mathrm{K}^{\mathrm{\gamma}}+\frac{\partial \mathrm{K}^{\prime}}{\partial \mathrm{a}_{\mathrm{y}}} \cdot \mathrm{a}_{\mathrm{y}}
$$

which is dependent upon lateral acceleration. In fact, it is this quantity, S, the lateral acceleration-dependent understeer gradient, which is the principal element determining the local slope of the non-linear handling diagram defined by Ervin $(1,2)$.

The calculation of critical velocity, or yaw stability boundaries, appearing in Figures 2-4 is based upon Equation $(B-5)$, or

$U_{c}=\left[\frac{-l_{e}^{\prime}-\frac{\partial l_{e}^{\prime}}{\partial a_{y}} \cdot a_{y}}{K^{\prime}+\frac{\partial K^{\prime}}{\partial a_{y}} \cdot a_{y}}\right]^{1 / 2}$

where $\ell_{e}^{\prime}$ and $K^{\prime}$ are defined as above; $\partial \ell_{\mathrm{e}}^{\prime} / \partial a_{\mathrm{y}}$ and $\partial \mathrm{K}^{\prime} / \partial \mathrm{a}_{\mathrm{y}}$ represent the variations of $\ell_{e}^{\prime}$ and $K^{\prime}$ with respect to lateral acceleration (see Appendix B). Noting that the denominator of the critical velocity expression in Equation (3) is simply the lateral acceleration-dependent understeer gradient, S, Equation (3) can be expressed as:

$$
U_{c}=\left[\frac{-\ell_{e}^{\prime}-\frac{\partial l_{e}^{\prime}}{\partial a_{y}} \cdot a_{y}}{s}\right]^{1 / 2}
$$



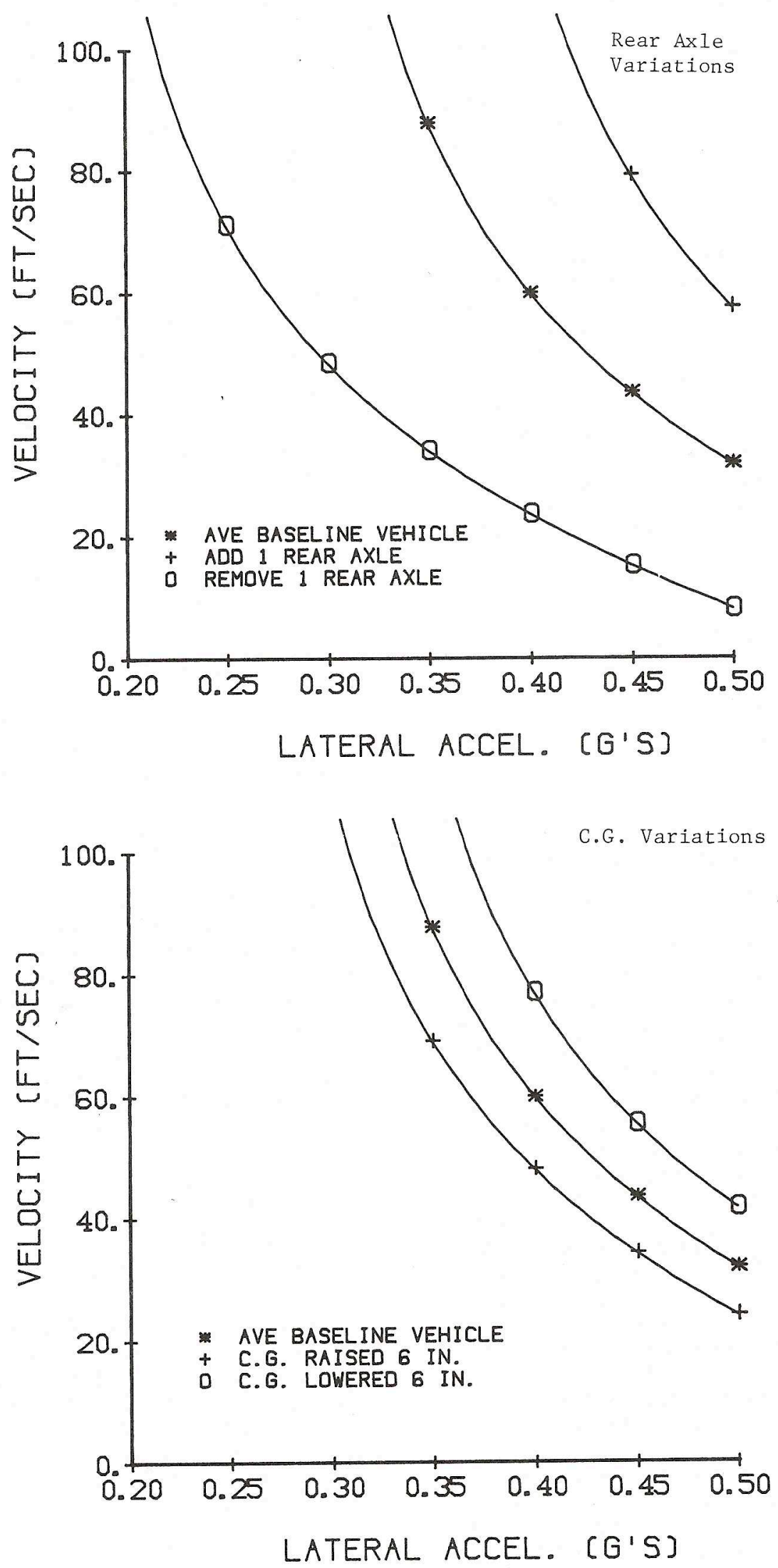

Figure 2. Rear axle and center of gravity height variations. 

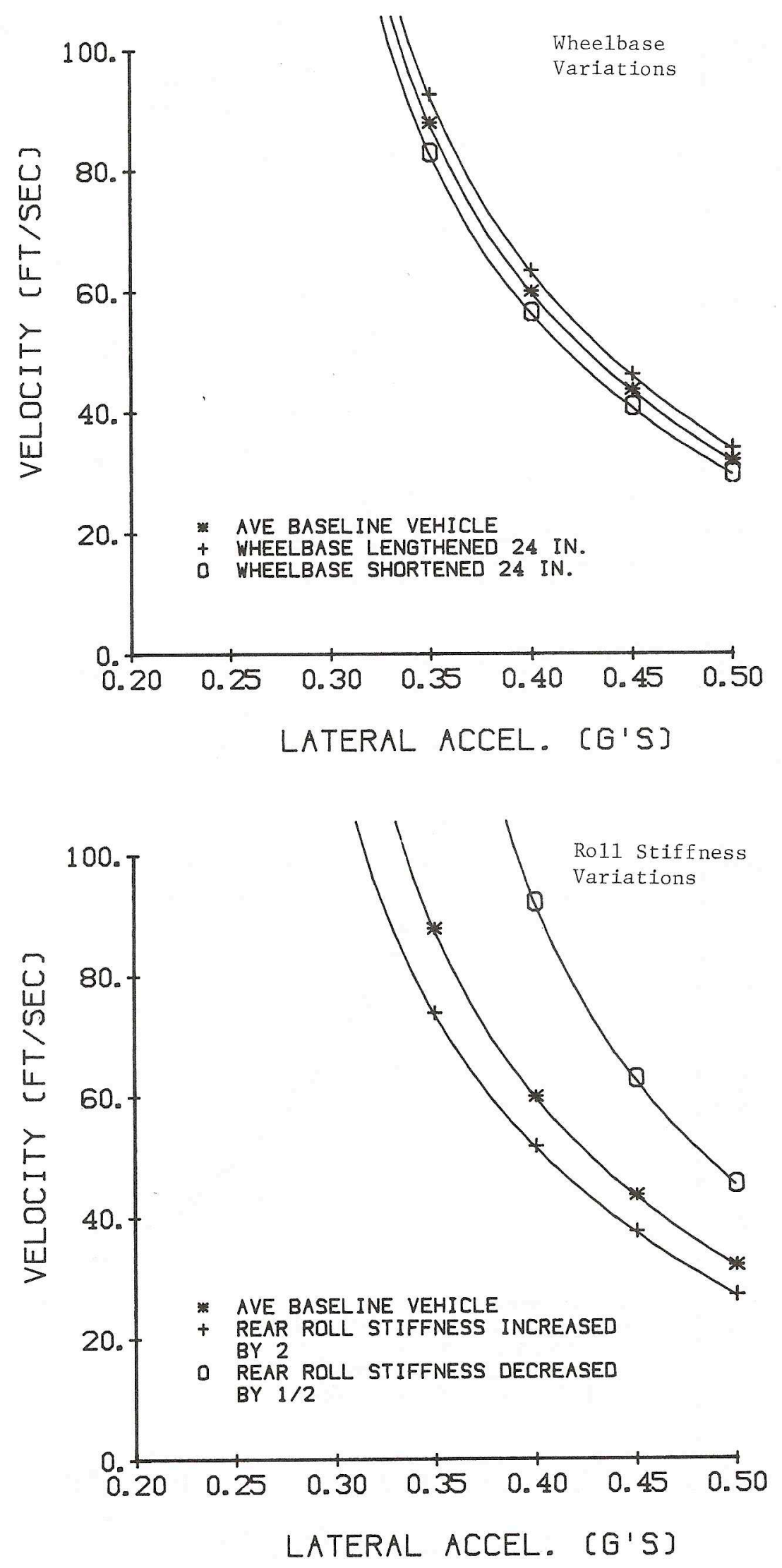

Figure 3. Wheelbase and roll stiffness variations. 

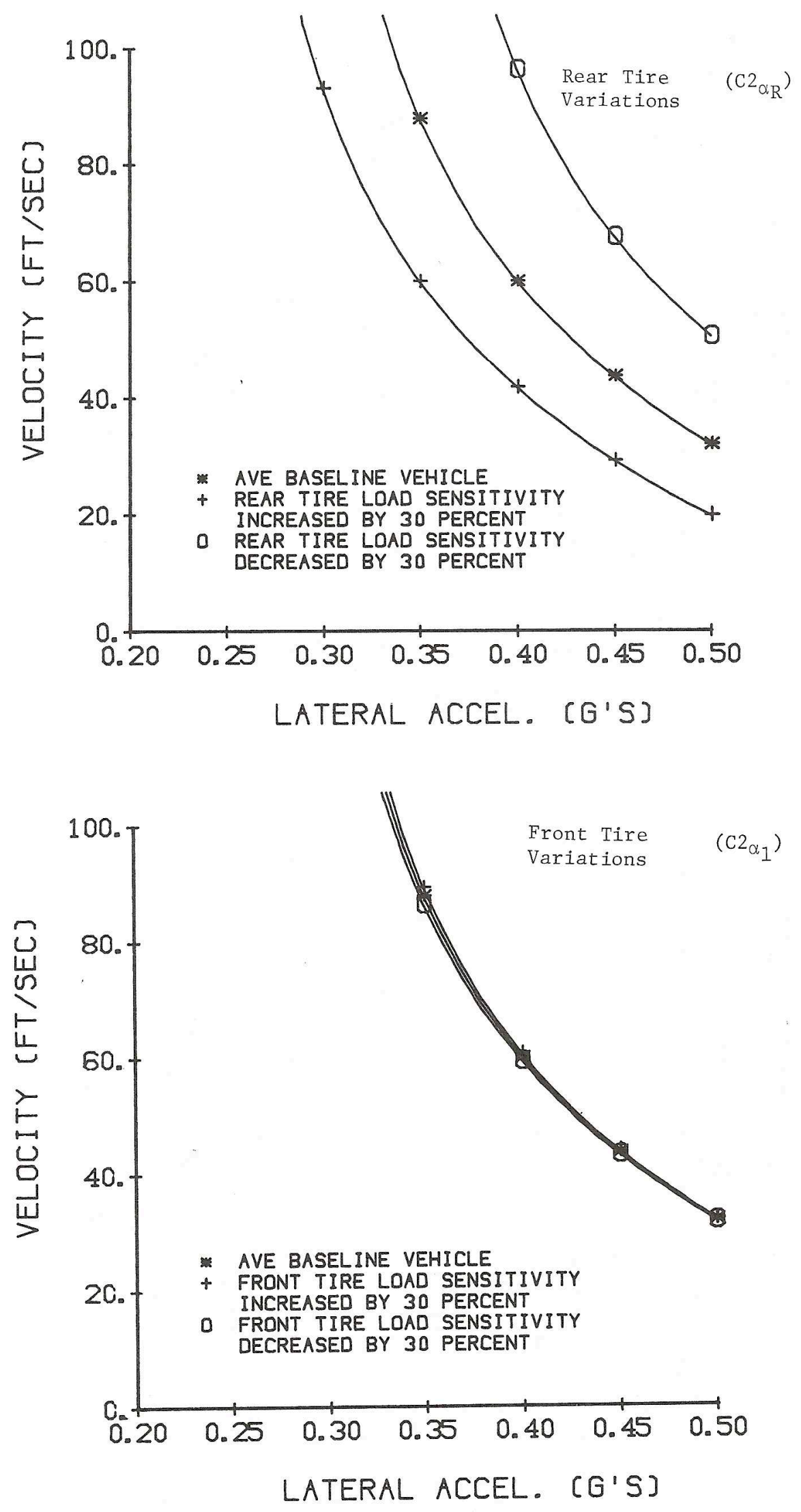

Figure 4. Tire property variations. 
If the quantity, $S$, is plotted as a function of lateral acceleration for some representative high c.g. heavy truck, we would obtain a graph of the form shown in Figure 5. We see that at
(As lateral acceleration increases further, additional lateral tire force losses deriving from shear-force-related properties of the truck tire, and not included here, would gradually

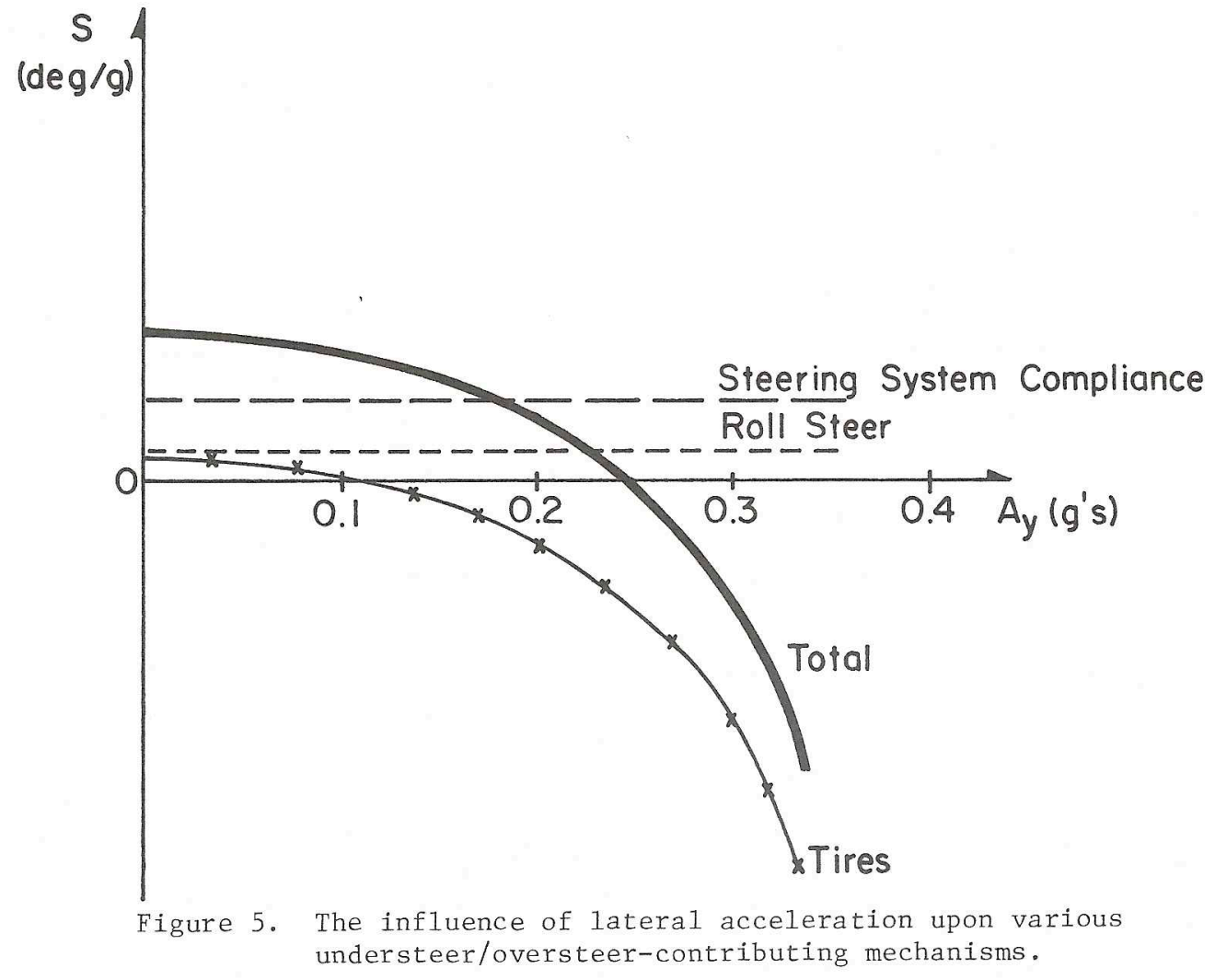

low levels of lateral acceleration the quantity $S$ has a positive value and falls off in a rapid, quadratic-like fashion as lateral acceleration increases above $0.2-0.3 \mathrm{~g}$. (The transition of this quantity from positive to negative values as lateral acceleration increases is analogous to the polarity of the slope of the non-linear handling diagram in reflecting the transition from understeer to oversteer.) Also shown in this figure are three additional lines representing various elements comprising the quantity $S$. Two of these elements, "Steering System Comp1iance" and "Ro11 Steer," appear as constant quantities on this plot; the one labeled "Tires" is the element contributing to the quadraticlike reduction in $\mathrm{S}$ as lateral acceleration is increased. (A value of $3 \mathrm{deg} / \mathrm{g}$ was assumed for these constant quantities in the calculations appearing in Figures 2-4.) The thrust of this figure illustrates, quite convincingly, that the constant-like understeer mechanisms of steering system compliance and roll steer are very quickly overwhelmed by the quadratic-1ike oversteer contributions deriving from the net loss of rear tire cornering stiffness as lateral acceleration begins exceeding $0.2-0.3 \mathrm{~g}$ for such vehicles. supplement the cornering stiffness losses discussed above.) Without having similar quadraticlike contributions from other understeer mechanisms, the vehicle designer is left with the following means for improving the directional stability of such vehicles: (1) decreasing fore/ aft roll stiffness distributions through increased front suspension and/or frame roll/torsional stiffness, or (2) selection of tires whose cornering stiffness varies more linearly than others with increasing load (i.e., less curvature in the $\mathrm{C}_{\alpha}$ vs. load plot), or (3) addition of more tires or axles at the rear of the vehicle. Items (1) and (3) would also serve to improve the roll stability of the vehicle.

\section{COMPUTER SIMULATION STUDY}

The following section describes the results of the computer simulation study which examined the turning response of three similar, though distinct, heavy truck vehicles, as represented by a comprehensive computer model. The principal difference between this study and the simplified 
analysis of the previous section is in the level of detail defining the mechanics of the vehicle and its dynamical behavior.

THE COMPUTER MODEL - The computer model.

(10) used here to simulate the turning response of the examined vehicles is similar in capability to other comprehensive computer models used for simulating commercial vehicle behavior $(12,13)$. It was developed for the purpose of predicting the directional and roll response of single- and multiple-articulated vehicles engaged in steering maneuvers which approach the rollover condition. The equations of motion were dereloped in such a fashion that it is possible to use the model for simulating vehicles with (1) up to four sprung masses and associated articulation points, (2) versatile placement of wheels and tires, and (3) most hitch mechanisms and constraints employed in heavy-duty commercial vehicles. The forward velocity of the lead unit is assumed to remain constant during the maneuver. Hence, each sprung mass is treated as a rigid body with five degrees of freedom: 1ateral, vertical, yaw, roll, and pitch. The axles are treated as beam axles which are free to roll and bounce with respect to the sprung mass to which they are attached.

ESTIMATION OF VEHICLE PARAMETERS - The above computer model was used to simulate the turning response of three different hypothetical vehicles which possessed mass distribution and geometric properties considered characteristic of a general class of high c.g. trucks (e.g., certain types of dump trucks, cement mixers, and front-end-loading trash haulers, some of which are peculiar to certain states or regional areas). The parameter estimates used to represent-this class of vehicles in the computer model were based upon simple field measurements-and photographs of these types of vehicles. In addition, UMTRI's resource of vehicle parameters, which include representative suspension and tire data, were also used to estimate parameter values considered characteristic of various vehicle components.

Table 1 lists the general description of three vehicles identified as Vehicle A, Vehicle $B$, and Vehicle $C$, which represent here, three possible vehicle configurations from the general class of vehicles described above. Figure 6 shows the cornering stiffness variation with vertical load assumed for both the front and rear tires. The tire data was taken from a previous study (5) in which various tire measurements were conducted on tires similar in size and construction to those commonly observed on vehicles of this class. The suspension rates shown in Table 1 are for the entire axle (left and right springs). Tag axles equipped with air suspensions were represented by low vertical spring rates $(2 \mathrm{~K})$ and high auxiliary roll stiffnesses. Careful attention was given to assembling computer model data sets, upon which the vehicle descriptions in Table 1 are based, so as to avoid portraying unrealistic ranges of geometric and mass distribution properties. Hence, the following computer simulation predictions, corresponding to Vehicles A, B, and C, should be viewed as representing a certain class of high c.g. trucks, and not applicable to trucks possessing moderate or low center of gravity heights.

COMPUTER SIMULATION RESULTS - The methodology, or computer-based technique, used for conducting the computer simulation study is described as follows: for a particular forward speed of the vehicle, a sequence of steady turns were conducted. Each steady turn during this sequence was slightly more severe than the one before due to an incremented steering angle. This process was continued until an instability developed, either in the form of rollover or yaw divergence. The forward velocity and lateral acceleration level at which the instability first occurred during each sequence was then recorded and used to define one point on the yaw/roll stability plot, similar to Figure 1. This process would then be repeated for several forward velocities until an adequate "mapping" of the yaw/roll stability boundary was achieved for each vehicle.

Figure 7 shows a representative time history result for Vehicle $C$, illustrating the yaw divergence phenomena and how it leads to roll instability if the steering angle remains fixed. This simulation run was conducted at a forward speed of $55 \mathrm{mph}$ and represents a velocitylateral acceleration point, at about 1 second, which is wel1 within the yaw-divergent/roll stable region of Figure 1 and moves, for the remaining time, toward the roll stability threshold. Shortly after 1 second, the continuously increasing yaw rate response, characteristic of yaw divergence, has begun. We observe that after 5 seconds the roll angle is exceeding 7 degrees and the rear inside tires are approaching lift-off. Note that the start of yaw divergence is clearly apparent within 1.5 seconds for this run, at a relatively low lateral acceleration level of $6 \mathrm{ft} / \mathrm{sec}^{2}(0.2 \mathrm{~g})$. In fact, turns as low in severity as $0.18 \mathrm{~g}^{\prime} \mathrm{s}$ were shown to produce yaw divergence (requiring more time to develop) in this vehicle at a forward speed of $55 \mathrm{mph}$.

Figure 8 summarizes, in the same manner as Figure 1, the results of the computer simulation study for Vehicles A, B, and C. The vertical lines represent the roll thresholds predicted for each vehicle; the lines curving upward to the left represent the yaw stability boundaries predicted for each vehicle. Also shown in this figure are two dashed lines which show the movement, leftward, of the yaw stability boundaries for Vehicles $A$ and $B$, as a result of having removed the rearmost axle from each vehicle.

The general range of yaw stability boundaries predicted by the computer simulation model in Figure 8 are observed to be somewhat more restrictive (located more to the left) than the simplified analysis of the previous section. 
Table 1. Vehicle Descriptions-Computer Simulation Study

\begin{tabular}{|c|c|c|c|c|c|c|}
\hline Vehicle & $\begin{array}{l}\text { Sprung Mass } \\
\text { c.g. Height }\end{array}$ & $\begin{array}{l}\text { No. of } \\
\text { Axles }\end{array}$ & Whee1base* & $\begin{array}{l}\text { Static Axle } \\
\text { Loads }(1 b / 1000)\end{array}$ & $\begin{array}{l}\text { Axle Suspension } \\
\text { Rate (1b/in/1000) }\end{array}$ & $\begin{array}{l}\text { Fore/Aft Roll** } \\
\text { Compliance Ratio }\end{array}$ \\
\hline A & $72^{\prime \prime}$ & 5 & $196^{\prime \prime}$ & $18 / 9.6 / 18 / 18 / 6$ & $4 / 2 / 15 / 15 / 2$ & 12 \\
\hline B & $78^{\prime \prime}$ & 5 & $189^{\prime \prime}$ & $18 / 13 / 13 / 13 / 13$ & $4 / 2 / 15 / 15 / 2$ & 16 \\
\hline
\end{tabular}

*Front axle to center-1ine of rear suspension

**Including auxiliary axle roll stiffness

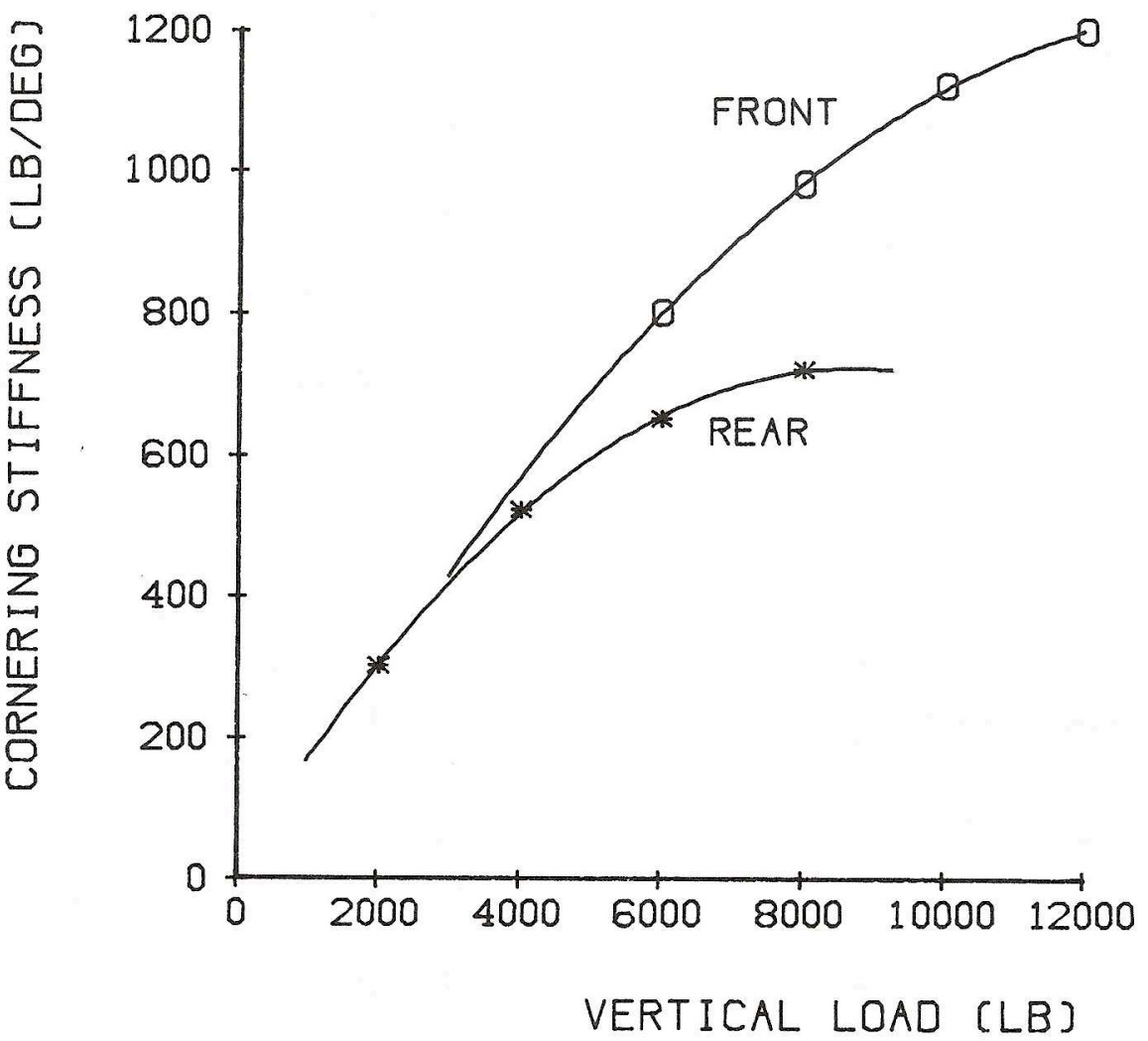

Figure 6. The variation of front and rear tire cornering stiffnesses with vertical load. 

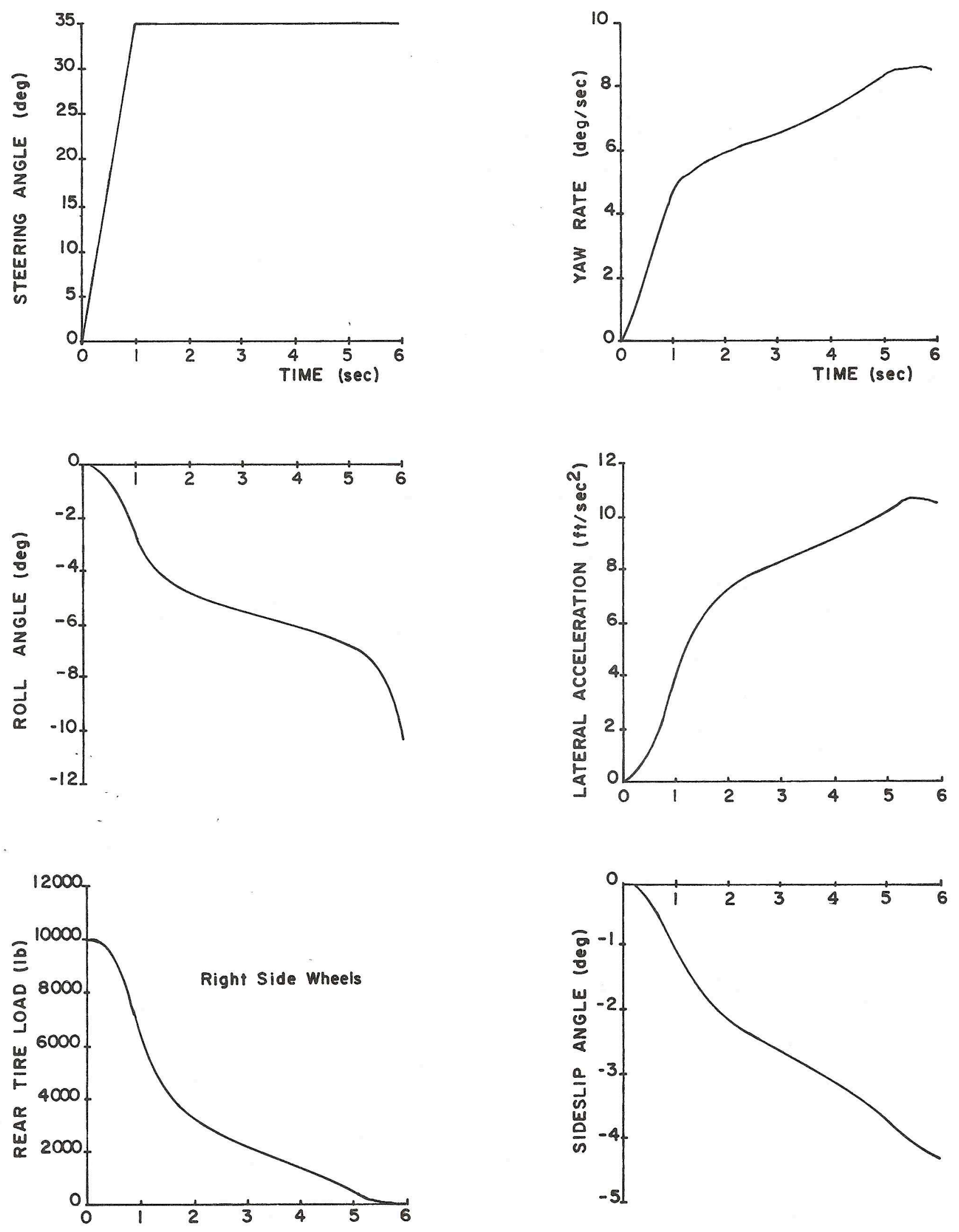

Figure 7. Illustration of yaw-divergence/rollover for Vehicle C. 


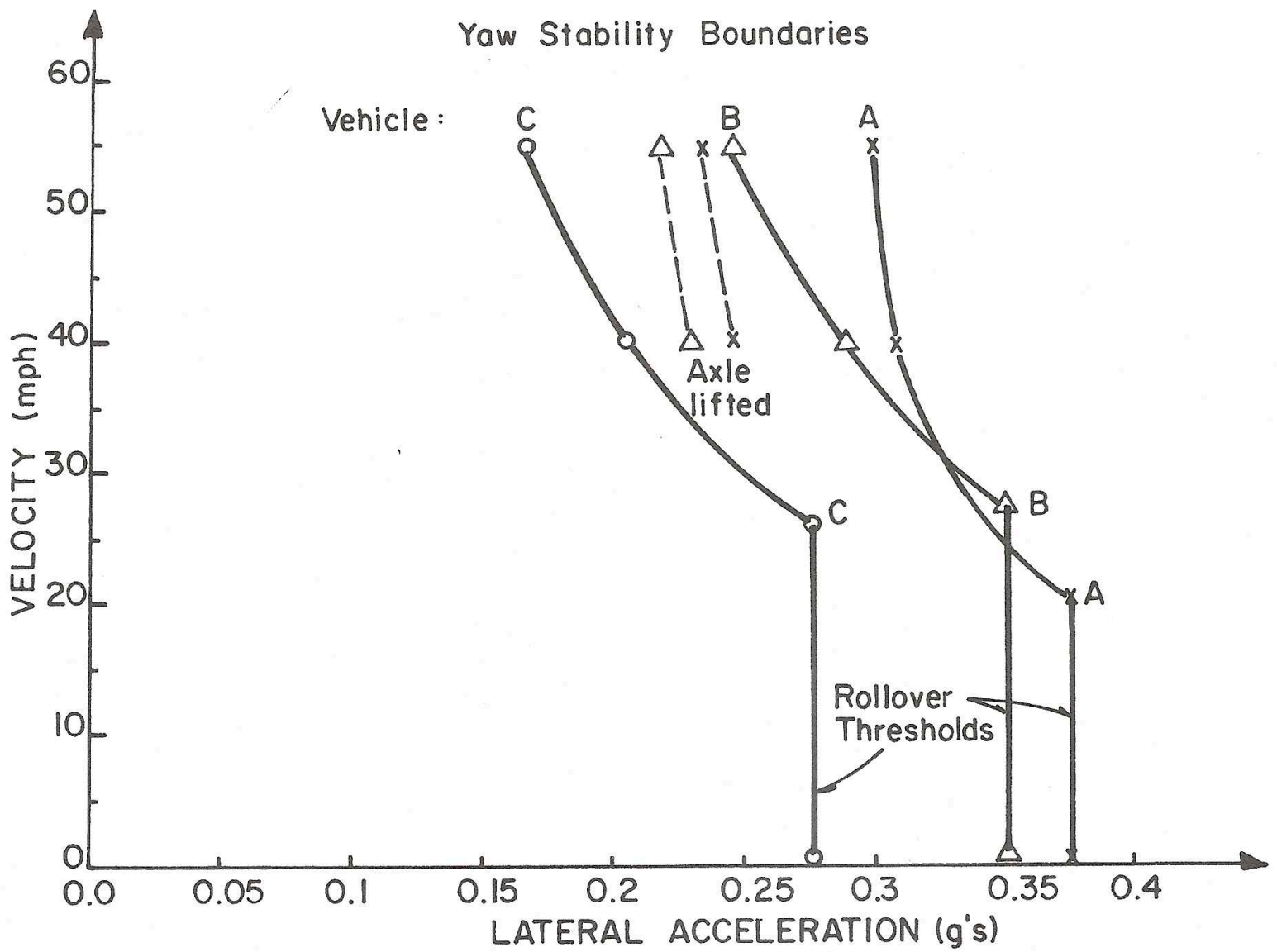

Figure 8. Summary of the yaw/roll stability findings from the computer simulation study.

This difference is, of course, understandable since: (1) the static side-to-side load transfer assumption used in the simplified analysis is especially conservative, and (2) additional, mild non-linearities present in the computer simulation tire representation at low lateral acceleration levels further contribute to the destabilization process. Recall, however, that the primary purpose of the simplified sensitivity analysis was to aid in understanding the development of yaw divergence, and also, to provide a simple means of examining the sensitivity of yaw stability boundaries to vehicle parameter variations. Furthermore, if Figure 8 is viewed as a parameter variation exercise (i.e., removal of one or more axles, variations in c.g. heights and fore/aft roll stiffness), some of which are occurring simultaneously, many of the sensitivities suggested by the simplified analysis are strongly reflected in the computer simulation results.

The results of the computer simulation study presented in Figure 8 suggest that under steady turning conditions:

1) The maximum lateral acceleration operating range for these vehicles is greatest at low speeds, becoming increasingly restricted as speed increases.
2) Increasing the number of rear axles and/ or lowering the center of gravity height are effective methods for reducing the likelihood of yaw instabilities occurring at highway speeds in vehicles of this general class.

3) Yaw instabilities are not likely to be encountered at speeds less than $25 \mathrm{mph}$ for this class of vehicles. And more specifically,

4) Moderate wheelbase trucks which (a) possess sprung mass center of gravity heights greater than $80^{\prime \prime}$, (b) are equipped with a rear tandem suspension of average stiffness, (c) possess tires of average traction which exhibit cornering stiffness variation with vertical load similar to that shown in Figure 6, and (d) are loaded in a manner similar to Vehicle $C$ of Table 1, are capable of developing yaw instabilities at lateral acceleration levels less than $0.2 \mathrm{~g}$ while operating on horizontal surfaces at speeds above $40 \mathrm{mph}$.

5) A representative range of rollover thresholds is 0.28 to $0.38 \mathrm{~g}^{\prime} \mathrm{s}$ for the group of vehicles examined in this study. 
CLOSED LOOP STABILIZATION OF YAW DIVERGENT VEHICLES

The results of the previous sections suggest that certain high-center-of-gravity trucks, operating at highway speeds can exhibit yaw divergence behavior under relatively low lateral acceleration turning conditions. If so, a natural question which arises is, "Can drivers, through normal compensating or corrective steering action, stabilize the vehicle and maintain adequate maneuverability under these conditions?" To begin to address this question, a sma11 and admittedly cursory study was conducted to examine the question of closed-loop stabilization of yaw divergent vehicles within the yaw divergent/roll stable region of Figure 1 . That is, referring to Figure 1 , operation within a region to the right of the vehicle's yaw stability boundary and to the left of its rollover threshold.

Results of several computer simulation runs performed with the aid of a driver model, indicated that stabilization of the closed-loop (driver-controlled) system was possible while retaining maneuverability or path control in this regime. However, both stability and maneuverability degrade rapidly as lateral acceleration approaches the rollover threshold.

The comprehensive computer model (13) and associated driver model (14) were employed in this activity to simulate the closed-loop driver/ vehicle system. Average driver model parameters were used to simulate the driver control characteristics. Figures 9 and 10 show computer simulation results for a three-axle vehicle, similar to Vehicle C (but with reduced axle loadings of $16 \mathrm{~K} / 16 \mathrm{~K} / 16 \mathrm{~K}$ and 75 -inch $\mathrm{c} . \mathrm{g}$. height), performing a $50 \mathrm{mph}$ closed-1oop circular turn at $0.19 \mathrm{~g}^{\prime \prime} \mathrm{s}$ and $0.26 \mathrm{~g}^{\prime} \mathrm{s}$, respectively. Figure 9 corresponds to a lateral acceleration level which is below this vehicles $\mathrm{s}$ yaw stability boundary, while Figure 10 corresponds to a point above the vehicle's yaw stability boundary but below its rollover threshold. Both driver/vehicle systems track the circular paths with little difficulty. However, as can be seen in these two figures, the nature of the closed-1oop steering functions are very dissimilar. Figure 9 shows a relatively constant steer control after $3-4$ seconds (as one would expect), while Figure 10 shows a slow oscillatory steering control.

The time-varying, closed-loop steering control characteristics for the yaw divergent vehicle in Figure 10 can be understood by noting that a yaw divergent vehicle (without driver contro1) will respond to any disturbance by diverging away from an otherwise straight-line path. Clearly, a fixed level, closed-1oop steering control, as is appropriate for following a circular turn in the case of a yaw stable vehicle, is not appropriate for a yaw divergent vehicle. Instead, a continually changing steering control, which constantly corrects the pathdivergence tendencies of the more dynamically varying yaw divergent vehicle, is the required steering control strategy. (If the maneuver, as described here, lasted for a long enough period of time, the oscillatory steering control would eventually die out, settling on a quasilike fixed value.) Needless to say, such vehicle characteristics require very attentive drivers under these circumstances and are hardly desirable.

The purpose of presenting results from this brief study is not to sanction or encourage closed-loop operation within the yaw divergent/ roll stable regime, but instead, to try to address certain questions and prevailing notions that entering this regime will precipitate a suddenly unstable or uncontrolled driver/vehicle system. Based on these results, there appears to be nothing "magical" about the yaw stability boundary for closed-loop operation except for the requirement of drivers to use a continuously varying (and presumably undesirable and more demanding) steering control to stabilize the directional vehicle dynamics at lateral acceleration levels above this boundary. In addition, it was observed that the directional stability of the closed-loop driver/vehicle system is gradually degraded as lateral acceleration operating conditions are increased from low levels to the rollover threshold.

One last example, using the same model, demonstrates the yaw stabilizing benefits derived from roadway superelevation. Figure 11 shows a limit-level $0.3 \mathrm{~g}, 55 \mathrm{mph}$, closed-1oop circular turn by the same vehicle (Figs. 9, 10) on a flat horizontal road and operating above its yaw stability boundary. Figure 12 shows the same maneuver repeated, but now on a roadway which gradually increases in superelevation to a fixed value of eight percent. While the horizontal-plane lateral acceleration is still $0.3 \mathrm{~g}^{\prime} \mathrm{s}$ in negotiating this turn, the presence of superelevation reduces the lateral tire force requirements to maintain the same circular path and also decreases the side-to-side load transfer. Since rear-end load transfer/tire load sensitivity is the principal mechanism responsible for yaw-divergent vehicle dynamic behavior, a stabilizing effect should accrue from the presence of superelevation. Figure 12 clearly reflects such an improvement with a yaw-stable, closed-loop steering control similar to that shown in Figure 9, and greatly reduced side-toside load transfer.

These last examples raise the interesting question of whether the yaw divergence phenomenon, as suggested by these computer-based findings, and so effectively countered by superelevated curves and to some extent by driver steering control, should be, in a very practical sense, a real concern. That is, since the development of yaw divergence requires high-speed turning on primarily horizontal-like surfaces, do ample opportunities or scenarios actually exist within the highway system for vehicles, such as those studied here, to develop yaw instabilities? Does the level of superelevation in expressway curves, exit ramps, and rural highway curves, as 

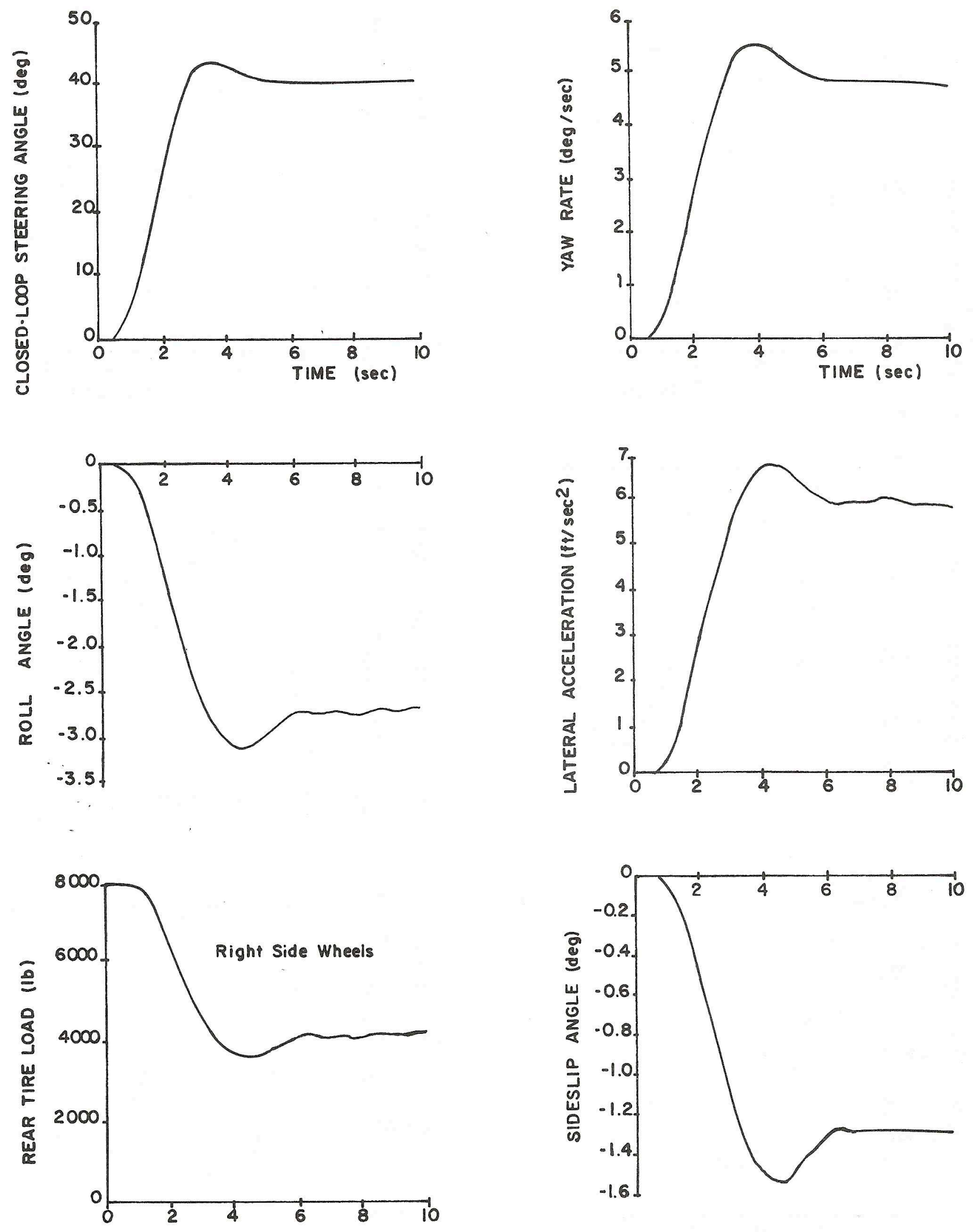

Figure 9. Closed-1oop (driver-controlled) circular turning maneuver, operating below the vehicle yaw-stability boundary. 

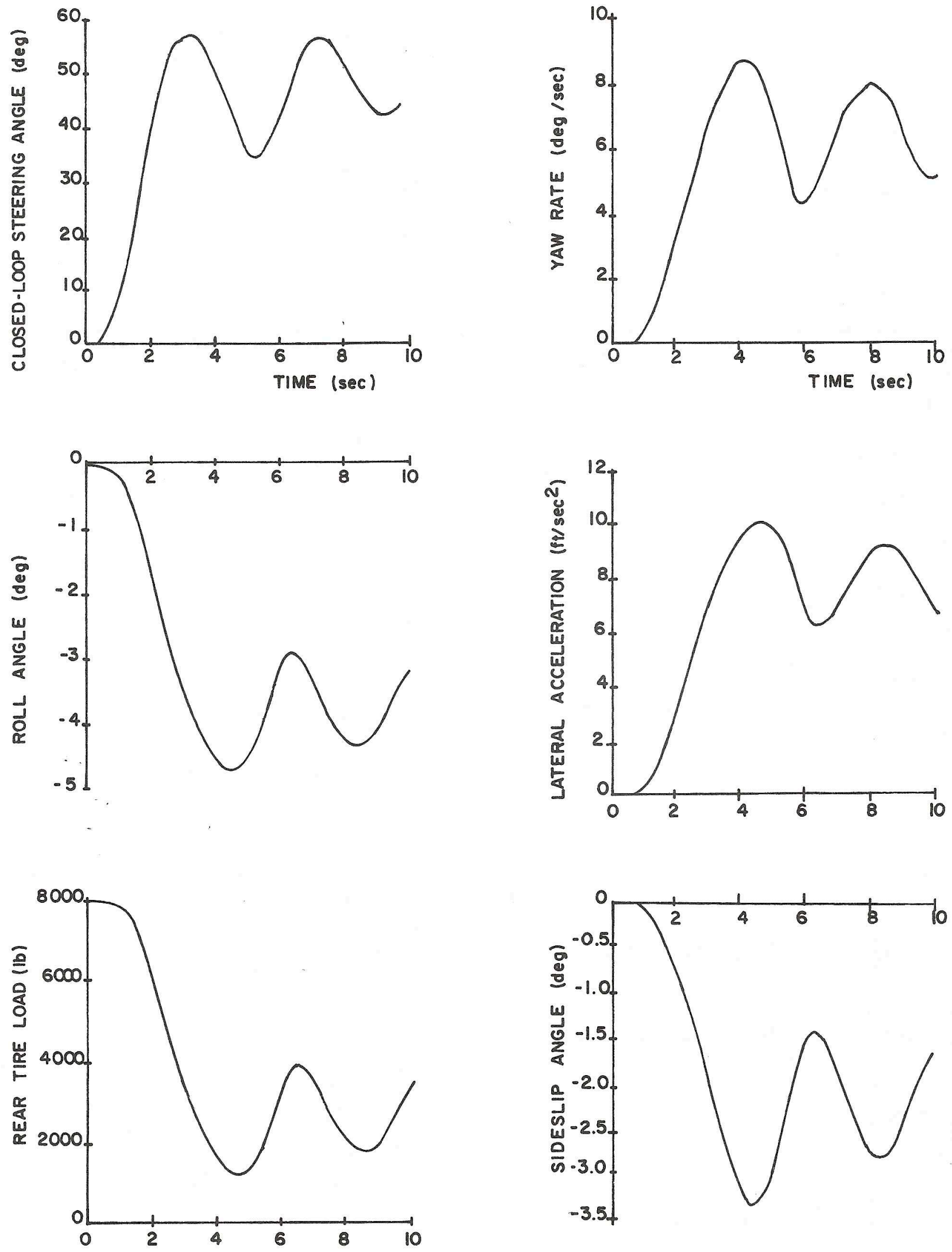

Figure 10. Closed-loop (driver-controlled) circular turning maneuver, operating above the vehicle yaw-stability boundary. 

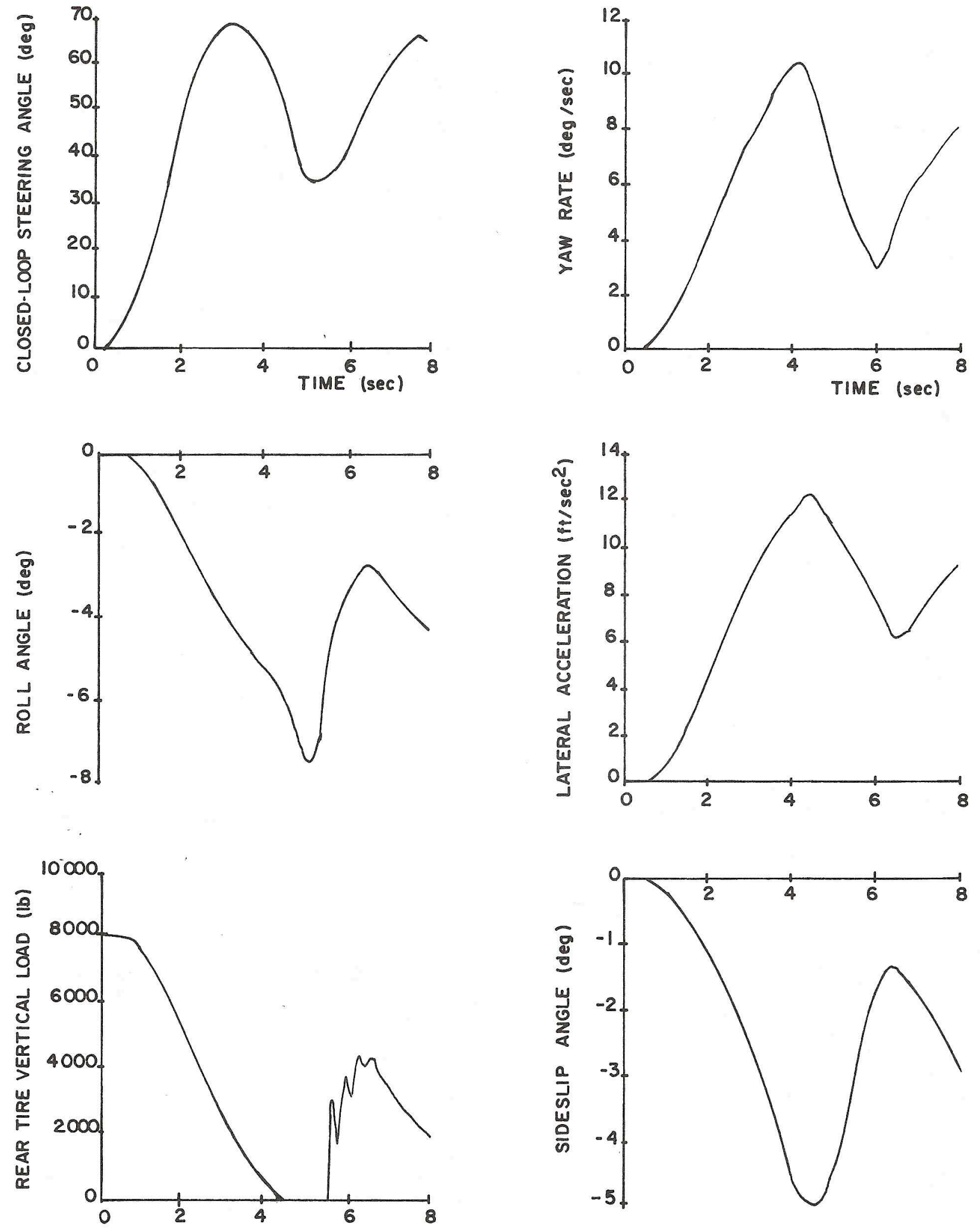

Figure 11. Closed-loop (driver-controlled) limit-level turning maneuver on a flat, horizontal road surface. 

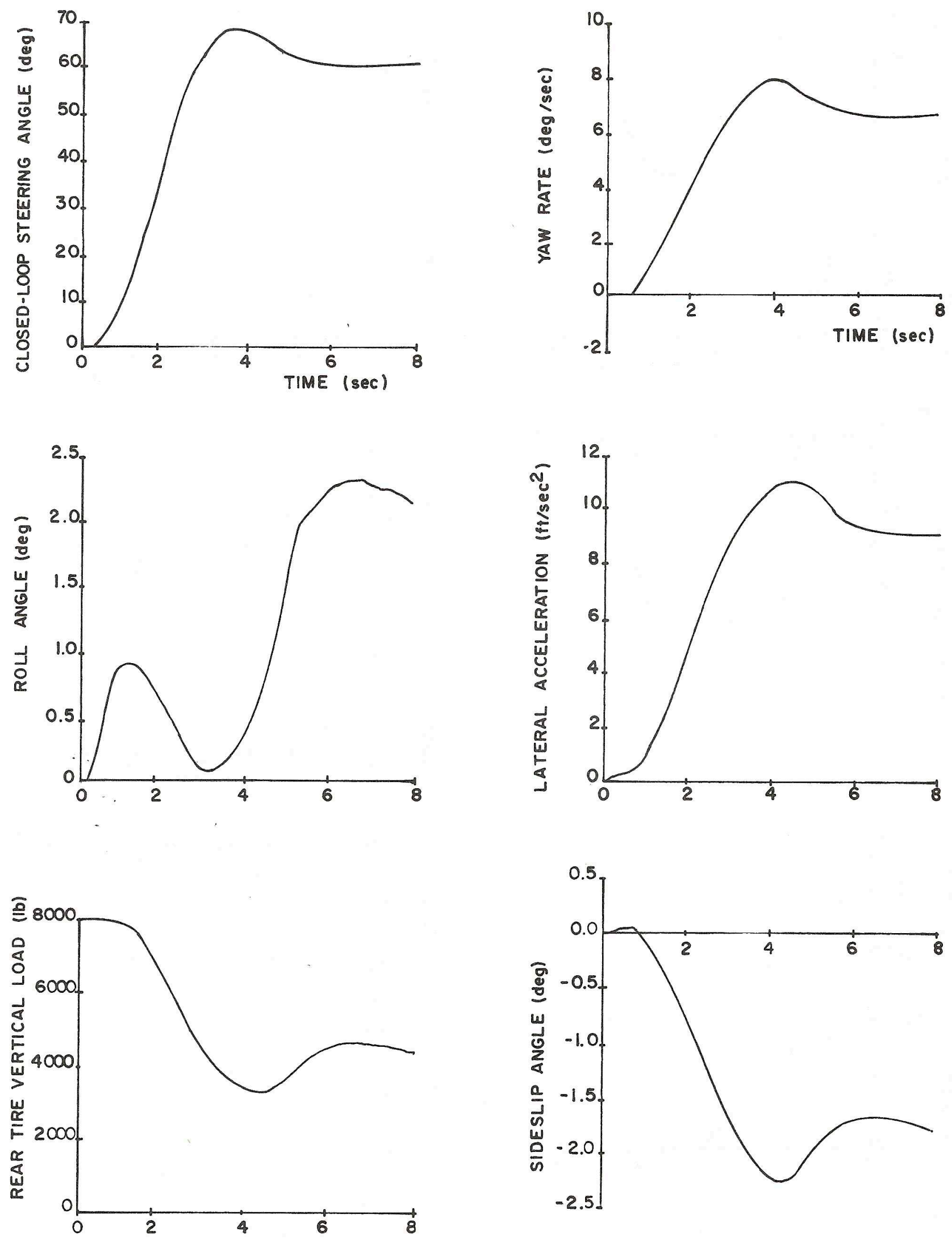

Figure 12. Repeat of the maneuver shown in Fig. 11 on an $8 \%$ superelevated curve. 
determined by common design practice, effectively negate the likelihood of yaw instabilities occurring in such vehicles? To what extent are actual drivers capable of detecting, controlling, and overcoming yaw-divergent behavior of certain vehicles? While such questions are clearly pertinent and should be pursued, it is also true that the design of heavy truck vehicles, so as to greatly diminish or eliminate the possibility of yaw instability occurrences, is undoubtedly the most effective means for counteracting this potential issue.

\section{SUMMARY AND CONCLUSIONS}

The computer-based results presented in this paper suggest that certain heavy trucks, characterized primarily by high centers of gravity, can develop yaw divergence instabilities during high-speed steady turns at relatively low levels of lateral acceleration. A simplified analysis, directed toward identifying the sensitivity of yaw stability thresholds to typical vehicle parameter variations, was shown to predict reasonable results when compared to results of a more comprehensive computer simulation study. A more thorough examination of the dynamical behavior of these vehicles during steady turning was conducted with the use of comprehensive computer models used for simulating vehicle-driver-roadway interactions.

Specific conclusions, applicable to the class of high-center-of-gravity trucks examined here, and based upon the results of the computer simulation study are:

A) Yaw divergence behavior during steady turning is possible in such vehicles operating at elevated speeds and relatively low lateral acceleration levels on flat horizontal surfaces.

B) The occurrence of yaw divergence during steady turning conditions will lead to rollover in the absence of corrective steering action and/or reduced speed.

C) The principal mechanism responsible for the production of yaw divergent behavior at low lateral acceleration levels and elevated speeds is the non-linear sensitivity of truck tire cornering stiffness to vertical load.

D) Although vehicle yaw divergence behavior may be stabilized by corrective steering actions of drivers, the margin of stability of such driver-controlled systems is significantly less than similar driver/vehicle systems possessing stable yaw dynamics.

E) The presence of superelevation in highway curves acts not only to contribute roll stabilization to such vehicles, but is also a particularly powerful means for reducing the likelihood of yaw divergence.

F) Reasonable vehicle-related modifications which could be performed to increase the yaw/roll stability of these vehicles are: (1) reduction in fore/aft roll stiffness distribution, (2) use of additional tires or axles (non-steering) at the rear of the vehicle,
(3) lowering of the center of gravity, and (4) selection of rear tires with more linear-like variation of cornering stiffness with vertical load.

\section{ACKNOWLEDGEMENT}

The work reported here was largely supported by the National Highway Traffic Safety Administration under Contract Number DTNH22-80-C-07344 for the project entitled, "Parametric Analysis of Heavy Truck Dynamic Stability." The Contract Technical Manager for NHTSA was Mr. Robert M. Clarke. The Project Director at UMTRI was Mr. Christopher B. Winkler. Additional support was provided by the Federal Highway Administration under Contract Number FH-11-9577 for the project "Measurement of Pavement-Truck Interaction Under Experimental Conditions," for which Dr. R. Hegmon served as Contract Manager. The Project Director at UMTRI was Mr. Robert D. Ervin. The author would also like to acknowledge the help and consultation of Dr. Chalasani Mallikarjunaro in performing certain computer simulation runs while at UMTRI.

\section{REFERENCES}

1. R.D. Ervin, et a1., "The Yaw Stability of Tractor-Semitrailers During Cornering." Final Report on Contract DOT-HS-7-01602, HSRI Report No. UM-HSRI-79-21, June 1979.

2. R.D. Ervin and C. Mallikarjunarao, "A Study of the Yaw Stability of TractorSemitrailer Combinations." Proceedings of the 7th IAVSD Symposium on Dynamics of Vehicles on Roads and Tracks, Cambridge, England, September 1981.

3. H.B. Pacejka, "Simplified Analysis of Steady-State Turning Behavior of Motor Vehicles." Parts 1-3. Vehicle System Dynamics, 2, 1973 , pp. 161-204.

4. L. Segel and R.D. Ervin, "The Influence of Tire Factors on Trucks and Tractor-Trailers." Vehicle System Dynamics, Vol. 10, No. 1, February 1981.

5. R.D. Ervin, et a1., "Effects of Tire Properties on Truck and Bus Handling." Report No. DOT-HS-802 141 as prepared by the Highway Safety Research Institute on Contract DOT-HS4-00943, December 1976.

6. H. Isermann, "Overturning Limits of Articulated Vehicles with Solid and Liquid Loads." Motor Industry Research Assoc., Translation No. 58/70, 1970.

7. D.W.G. Miller and N.F. Barter, "Rollover of Articulated Vehicles." I. Mechn. Engr. Conference on Vehicle Safety Legislation, Paper C203/73, 1973.

8. F. Gauss, et a1., "Calculation of the Overturn Resistance of Tractor-Semitrailer Combinations." Motor Industry Research Assoc., Translation No. 22/76, 1976.

9. R.N. Kemp, B.P. Chinn, and G. Brock, "Articulated Vehicle Roll Stability: Methods of Assessment and Effects of Vehicle Characteristics." TRRL Report 788. 
10. C. Mallikarjunarao, "Road Tanker Design: Its Influence on the Risks and Economics of Transporting Gasoline in Michigan." Ph.D. Thesis, The University of Michigan, December 1981.

11. C. Mallikarjunarao, R.D. Ervin, and L. Sege1, "Ro11 Response of Articulated Motor Trucks During Steady-Turning Maneuvers." Presented at the ASME Annual Winter Meeting, Phoenix, Ariz., November 14-19, 1982.

12. T.D. Gillespie, et al., "Truck and Tractor-Trailer Dynamic Response SimulationT3DRS:V1." User's Manual, Contract No. DOT-FH11-9330, HSRI, The Univ. of Michigan, Report No. UM-HSRI-79-38-1, June 1979.

13. C.C. MacAdam, et a1., "A Computerized Model for Simulating the Braking and Steering Dynamics of Trucks, Tractor-Semitrailers, Doubles, and Triples Combinations." User's Manua1, PHASE 4, HSRI, The Univ of Michigan, Report No. UM-HSRI-80-58, September 1, 1980.

14. C.C. MacAdam, "Application of an Optimal Preview Control for Simulation of Closed-Loop Automobile Driving." IEEE Transactions on Systems, Man, and Cybernetics, Vol. SMC-11, No. 6, June 1981, pp. 393-399:

15. C.B. Winkler and T.D. Gillespie, "On the Directional Response Characteristics of Heavy Trucks." Proceedings of the Fifth VSD2nd IUTAM Symposium on Dynamics of Vehicles on Roads and Tracks, Vienna, September 1977, pp. 165-183.

APPENDIX A - MODIFICATION OF THE CLASSICAL STEADY-TURNING EQUATION TO REFLECT TIRE CORNERING STIFFNESS DEPENDENCE UPON VERTICAL LOAD

Consider, from Reference (15), the conventional front wheel angle-path curvature relationship for a straight truck with tandem-axle rear suspension: -

$$
\begin{aligned}
\delta= & \frac{l e}{R}+K \frac{U^{2}}{R} \\
= & \frac{\ell}{R}\left[1+\left(\frac{\Delta^{2}+D^{2} C_{S_{R}} / C_{\alpha_{R}}}{l^{2}}\right)\left(1+\frac{C_{\alpha_{R}}}{C_{\alpha_{1}}}\right)\right] \\
& +M \frac{U^{2}}{R}\left[\frac{b}{l C_{\alpha_{1}}}-\frac{a}{\ell C_{\alpha_{R}}}\right]
\end{aligned}
$$

where

$$
\begin{aligned}
& \delta \text { is the front-wheel angle } \\
& R \text { is the path radius } \\
& U \text { is forward velocity }
\end{aligned}
$$

and

$$
\ell_{e}=\ell\left[1+\left(\frac{\Delta^{2}+D^{2} C_{S_{R}} / C_{\alpha_{R}}}{\ell^{2}}\right)\left(1+\frac{{ }_{\alpha_{R}}}{C_{\alpha_{1}}}\right)\right]
$$

is the "effective" wheelbase, related to

\& the actual vehicle wheelbase (front suspension to center of rear tandem suspension),

$\Delta$ one-half the rear tandem axle spread,

D one-half the dual tire spacing,

$\mathrm{C}_{\mathrm{S}_{\mathrm{R}}}$ the total rear tire longitudinal stiffness, $\mathrm{C}_{\alpha}$ the total rear tire cornering stiffness, and $\mathrm{C}_{\alpha_{1}}^{\alpha_{\mathrm{R}}}$ the total front tire cornering stiffness,

and,

$$
K=M\left[\frac{b}{l C_{\alpha_{1}}}-\frac{a}{l C_{\alpha_{R}}}\right]
$$

or

$$
\mathrm{K}=\left[\frac{\mathrm{W}_{1}}{\mathrm{C}_{\alpha_{1}}}-\frac{\mathrm{W}_{\mathrm{R}}}{\mathrm{C}_{\alpha_{\mathrm{R}}}}\right] / \mathrm{g}
$$

is the classical understeer gradient, related to the additional parameters

M the vehicle mass

a the distance from the c.g. to the front axle

$b$ the distance from the $\mathrm{c} \cdot \mathrm{g}$. to the center of the rear suspension

$W_{1}$ the static front suspension load

$\mathrm{W}_{\mathrm{R}}$ the static rear suspension load

$g$ the gravitational acceleration

For an actual vehicle, $\mathrm{K}$ is, of course, comprised of additional elements contributing understeer, such as steering system compliance and roll-steer effects, which are being ignored in the analysis that follows.

If the cornering stiffness, $C_{\alpha}^{\prime}$, of a single tire is now treated as the following function of vertical load, $\mathrm{F}_{\mathrm{Z}}$,

$\mathrm{C}_{\alpha}^{\mathrm{p}}\left(\mathrm{F}_{\mathrm{z}}\right)=\mathrm{C} 0_{\alpha}+\mathrm{C} 1_{\alpha}\left(\mathrm{F}_{z}-\mathrm{F}_{z_{0}}\right)+\mathrm{C} 2_{\alpha}\left(\mathrm{F}_{z}-\mathrm{F}_{z_{0}}\right)^{2}$

where

$\mathrm{CO}_{\alpha}$ is the cornering stiffness prevailing at the static or nominal load, $F_{z_{0}}$

$\mathrm{Cl}_{\alpha}$ is the linear variation of cornering stiffness with vertical load, about the nominal load, $\mathrm{F}_{z_{\mathrm{O}}}$

and $\mathrm{C} 2 \mathrm{is}$ the quadratic variation of cornering stiffness with vertical load, about the nominal load, $\mathrm{F}_{\mathrm{z}_{\mathrm{O}}}$

most $C_{\alpha}$ versus $F_{z}$ measurements for heavy truck tires can be accurately represented by this relationship. Hence, the cornering stiffness of a single tire on the front suspension can be expressed as: 


$$
\begin{aligned}
& \mathrm{C}_{\alpha_{1}}^{\prime}\left(\mathrm{F}_{z_{1}}\right)=\mathrm{CO}_{\alpha_{1}}+\mathrm{Cl}_{\alpha_{1}}\left(\mathrm{~F}_{z_{1}}-\mathrm{F}_{\mathrm{z}_{\mathrm{o}_{1}}}\right) \\
& +\mathrm{C} 2 \alpha_{1}\left(\mathrm{~F}_{\mathrm{z}_{1}}-\mathrm{F}_{\mathrm{z}_{\mathrm{o}_{1}}}\right)^{2}
\end{aligned}
$$

and, for a single tire on the rear suspension:

$$
\begin{aligned}
C_{\alpha_{R}}^{p}\left(F_{z_{R}}\right)= & { }^{C 0} \alpha_{R}+C 1_{\alpha_{R}}\left(F_{z_{R}}-F_{z_{o_{R}}}\right) \\
& +\mathrm{C} 2{ }_{\alpha_{R}}\left(F_{z_{R}}-F_{z_{o_{R}}}\right)^{2}
\end{aligned}
$$

Introduction of lateral acceleration-induced front and rear side-to-side load transfers, $\Delta W_{1}$ and $\Delta W_{R}$, proportioned by fore/aft roll stiffness distributions, produces the conservative static approximations:

$\Delta W_{1}=\frac{h}{T_{1}} W\left(\frac{K_{1}}{K_{1}+K_{R}}\right) a_{y}$

$\Delta W_{R}=\frac{h}{T_{R}} W\left(\frac{K_{R}}{K_{1}+K_{R}}\right) a_{y}$

where

$$
\mathrm{h} \text { is the total vehicle c.g. height }
$$

$\mathrm{T}_{1, \mathrm{R}}$ are the front, rear track distances

$W$ is the total vehicle weight

$\mathrm{K}_{1}$ is the front suspension roll stiffness

$\mathrm{K}_{\mathrm{R}}$ is the rear suspension roll stiffness

and $a_{y}$ is the vehicle lateral acceleration in
$g^{\prime} s$.

Left and right prevailing loads for both the front and rear axles can therefore be approximated for any given vehicle lateral acceleration, ay, as:

$$
\begin{aligned}
& \left.\mathrm{F}_{z_{1}}\left(a_{y}\right)\right|_{\text {left }}=F_{z_{1}}+\Delta W_{1}\left(a_{y}\right) \\
& \left.F_{z_{1}}\left(a_{y}\right)\right|_{\text {right }}=F_{z_{1}}-\Delta W_{1}\left(a_{y}\right)
\end{aligned}
$$

and

$$
\begin{aligned}
& \left.F_{z_{R}}\left(a_{y}\right)\right|_{\text {left }}=F_{z_{o_{R}}}+\Delta W_{R}\left(a_{y}\right) \\
& \left.F_{z_{R}}\left(a_{y}\right)\right|_{\text {right }}=F_{z_{o_{R}}}-\Delta W_{R}\left(a_{y}\right)
\end{aligned}
$$

Substitution of the above left and right vertical tire loads, deriving from load transfer during cornering, into the $\mathrm{C}_{\alpha}^{\gamma}\left(\mathrm{F}_{z}\right)$ expressions, Equations (A-7, A-8), and noting that the linear vertical load variations cancel one another when summed side to side, we are left with the following total cornering stiffness equations for front and rear suspensions expressed as a quadratic function of vehicle lateral acceleration, $a_{y}$ :

$$
\begin{aligned}
c_{\alpha_{1}} & =2\left[\mathrm{CO}_{\alpha_{1}}+\mathrm{C}_{\alpha_{1}} \Delta \mathrm{W}_{1}^{2}\right] \\
& =2\left[\mathrm{C}{ }_{\alpha_{1}}+\mathrm{C} 2 \alpha_{1}\left(\frac{\mathrm{h}}{\mathrm{T}_{1}}\right)^{2} \mathrm{w}^{2}\left(\frac{\mathrm{K}_{1}}{\mathrm{~K}_{1}+\mathrm{K}_{\mathrm{R}}}\right)^{2} \mathrm{a}_{\mathrm{y}}^{2}\right](\mathrm{A}-11)
\end{aligned}
$$

and

$$
\begin{aligned}
\mathrm{C}_{\alpha_{R}} & =\mathrm{N}\left[\mathrm{C0}{ }_{\alpha_{R}}+{ }^{C 2} \alpha_{R}\left(\frac{\Delta \mathrm{W}_{R}}{\mathrm{~N} / 2}\right)^{2}\right] \\
& =\mathrm{N} \cdot \mathrm{CO}_{\alpha_{\mathrm{R}}}+4 \mathrm{C} 2{ }_{\alpha_{R}} \Delta \mathrm{W}_{\mathrm{R}}^{2} / \mathrm{N} \\
& =\mathrm{N} \cdot \mathrm{C} 0_{\alpha_{R}}+\frac{4 \mathrm{C} 2 \alpha_{\mathrm{R}}}{\mathrm{N}}\left(\frac{\mathrm{h}}{\mathrm{T}_{\mathrm{R}}}\right)^{2} \mathrm{~W}^{2}\left(\frac{\mathrm{K}_{\mathrm{R}}}{\mathrm{K}_{1}+\mathrm{K}_{\mathrm{R}}}\right)^{2} \mathrm{a}_{\mathrm{y}}^{2}
\end{aligned}
$$

where $\mathrm{N}$ is the total number of tires on the rear suspension.

Substitution of these total front and rear cornering stiffnesses into Equations (A-3) and (A-5) produces the following lateral acceleration-dependent counterparts, $\ell_{e}^{\prime}$ and $K^{\prime}$ :

$$
\ell_{\mathrm{e}}^{\prime}=\ell \cdot[1+\mathrm{A} \cdot \mathrm{B}]
$$

where

$$
A=\frac{\Delta^{2}+D^{2} C_{S_{R}} /\left[N \cdot C 0_{\alpha_{R}}+\frac{{ }^{4 C 2} \alpha_{R}}{N}\left(\frac{h}{T_{R}}\right)^{2} W^{2}\left(\frac{K_{R}}{K_{1}+K_{R}}\right)^{2} a_{y}^{2}\right]}{l^{2}}
$$

and 


$$
\begin{aligned}
\mathrm{K}^{\prime}= & \frac{\mathrm{W}_{1}}{2\left[\mathrm{C}_{\alpha_{1}}+\mathrm{C} 2 \alpha_{1}\left(\frac{\mathrm{h}}{\mathrm{T}_{1}}\right)^{2} \mathrm{~W}^{2}\left(\frac{\mathrm{K}_{1}}{\mathrm{~K}_{1}+\mathrm{K}_{\mathrm{R}}}\right)^{2} \mathrm{a}_{\mathrm{y}}^{2}\right] \mathrm{g}} \\
& -\frac{\mathrm{W}_{\mathrm{R}}}{\left[\mathrm{N} \cdot \mathrm{CO} \alpha_{\alpha_{R}}+\frac{{ }^{4} \alpha_{\mathrm{R}}}{\mathrm{N}}\left(\frac{\mathrm{h}}{\mathrm{T}_{\mathrm{R}}}\right)^{2} \mathrm{~W}^{2}\left(\frac{\mathrm{K}_{\mathrm{R}}}{\mathrm{K}_{1}+\mathrm{K}_{\mathrm{R}}}\right)^{2} \mathrm{a}_{\mathrm{y}}^{2}\right] \mathrm{g}}
\end{aligned}
$$

$(\mathrm{A}-14)$

APPENDIX B - DIRECTIONAL STABILITY AND CALCULATION OF CRITICAL FORWARD VELOCITY

Rewriting Equation $(\mathrm{A}-1)$ as

$$
\delta=\frac{l^{\prime}}{R}+K^{\prime} \frac{U^{2}}{R}
$$

where $\ell_{e}^{\prime}$ and $K^{\prime}$ represent the lateral acceleration-dependent expressions $(A-13)$ and $(A-14)$, produces, by rearrangement, the path curvaturesteer angle relationship:

$$
\frac{1 / R}{\delta}=\frac{1}{l_{e}^{1}+K^{1} U^{2}}
$$

Consideration of infinite path curvature for finite steer levels during steady turning leads to the stability condition

$$
\frac{\partial(\delta)}{\partial\left(\frac{1}{R}\right)}>0
$$

or

$U^{2} \cdot \frac{\partial(\delta)}{\partial\left(a_{y}\right)}=l_{e}^{\prime}+K^{\prime} U^{2}+\left(\frac{\partial l_{e}^{\prime}}{\partial a_{y}}+\frac{\partial K^{\prime}}{\partial a_{y}} U^{2}\right) a_{y}>0$

The critical forward velocity, $\mathrm{U}_{\mathrm{C}}$, above which the vehicle becomes directionally unstable is obtained by solving Equation (B-4) for its zero condition:

$$
U_{c}=\left[\frac{-l_{e}^{\prime}-\frac{\partial l_{e}^{\prime}}{\partial a_{y}} \cdot a_{y}}{K^{\prime}+\frac{\partial K^{\prime}}{\partial a_{y}} \cdot a_{y}}\right]^{1 / 2}
$$

The partial derivatives appearing in Equation $(B-5)$ are obtained by differentiating Equations $(A-13)$ and $(A-14)$ with respect to $a_{y}$, viz.:

$$
\begin{aligned}
& \frac{\partial \ell_{e}^{\prime}}{\partial a_{y}}=\left[\frac{\partial A}{\partial a_{y}} \cdot B+\frac{\partial B}{\partial a_{y}} \cdot A\right] \cdot \ell \\
& =\left\{\frac{-8 D^{2} C_{S_{R}}{ }^{C 2} \alpha_{R}\left(\frac{h}{T_{R}}\right)^{2} W^{2}\left(\frac{K_{R}}{K_{1}+K_{R}}\right)^{2} a_{y}}{N e\left[N C \alpha_{\alpha_{R}}+\frac{4 C 2 \alpha_{R}}{N}\left(\frac{h}{T_{R}}\right)^{2} W^{2}\left(\frac{K_{R}}{K_{1}+K_{R}}\right)^{2} a_{y}^{2}\right]^{2}}\right\} \\
& \left\{1+\frac{{ }^{N C 0} \alpha_{R}+\frac{{ }^{4 C 2} \alpha_{R}}{N}\left(\frac{h}{T_{R}}\right)^{2} W^{2}\left(\frac{K_{R}}{K_{1}+K_{R}}\right)^{2} a_{y}^{2}}{2\left[C 0_{\alpha_{1}}+C 2 \alpha_{1}\left(\frac{h}{T_{1}}\right)^{2} W^{2}\left(\frac{K_{1}}{K_{1}+K_{R}}\right)^{2} a_{y}^{2}\right]}\right\}
\end{aligned}
$$$$
+\left\{\frac{8 \frac{{ }^{C} \alpha_{R}}{N}\left(\frac{h}{T_{R}}\right)^{2} W^{2}\left(\frac{K_{R}}{K_{I}+K_{R}}\right)^{2} a_{y}}{2\left[c_{\alpha_{1}}+C 2 \alpha_{1}\left(\frac{h}{T_{1}}\right)^{2} W^{2}\left(\frac{K_{1}}{K_{1}+K_{R}}\right)^{2} a_{y}^{2}\right]}\right.
$$$$
-\left[4 \mathrm{C} 2 \alpha_{1}\left(\frac{h}{T_{1}}\right)^{2} W^{2}\left(\frac{K_{1}}{K_{1}+K_{R}}\right)^{2} \cdot a_{y}\right]\left[N C 0_{\alpha_{R}}+\right.
$$$$
\left.\frac{\left.\frac{4 \mathrm{C} 2}{\mathrm{~N}} \alpha_{\mathrm{R}}\left(\frac{\mathrm{h}}{\mathrm{T}_{\mathrm{R}}}\right)^{2} \mathrm{w}^{2}\left(\frac{\mathrm{K}_{\mathrm{R}}}{\mathrm{K}_{1}+\mathrm{K}_{\mathrm{R}}}\right)^{2} \mathrm{a}_{\mathrm{y}}^{2}\right]}{2\left[\mathrm{C} \alpha_{\alpha_{1}}+\mathrm{C} 2 \alpha_{1}\left(\frac{\mathrm{h}}{\mathrm{T}_{1}}\right)^{2} \mathrm{w}^{2}\left(\frac{\mathrm{K}_{1}}{\mathrm{~K}_{1}+\mathrm{K}_{\mathrm{R}}}\right)^{2} \mathrm{a}_{\mathrm{y}}^{2}\right]^{2}}\right\rangle
$$$$
\left\{\frac{\Delta^{2}+D^{2} C_{S_{R}} /\left[N C 0 \alpha_{R}+\frac{{ }^{4 C 2} \alpha_{R}}{N}\left(\frac{h}{T_{R}}\right)^{2} W^{2}\left(\frac{K_{R}}{K_{I}+K_{R}}\right)^{2} a_{y}^{2}\right]}{l}\right\}
$$$$
\frac{\partial K^{p}}{\partial a_{y}}=-\frac{W_{1}{ }^{C 2} \alpha_{1}\left(\frac{h}{T_{1}}\right)^{2} W^{2}\left(\frac{K_{1}}{K_{1}+K_{R}}\right)^{2} a_{y}}{\left[\mathrm{C}_{\alpha_{1}}+{ }^{C} 2 \alpha_{1}\left(\frac{h}{T_{1}}\right)^{2} W^{2}\left(\frac{\mathrm{K}_{1}}{\mathrm{~K}_{1}+\mathrm{K}_{\mathrm{R}}}\right)^{2} \mathrm{a}_{\mathrm{y}}^{2}\right]^{2} \mathrm{~g}}
$$$$
+\frac{8 \mathrm{~W}_{\mathrm{R}} \cdot \frac{{ }^{\mathrm{C} 2} \alpha_{R}}{\mathrm{~N}}\left(\frac{\mathrm{h}}{\mathrm{T}_{\mathrm{R}}}\right)^{2} \mathrm{~W}^{2}\left(\frac{\mathrm{K}_{\mathrm{R}}}{\mathrm{K}_{1}+\mathrm{K}_{\mathrm{R}}}\right)^{2} \mathrm{a}_{\mathrm{y}}}{\left[\mathrm{NCO} \alpha_{\mathrm{R}}+\frac{{ }^{\mathrm{C} 2} \alpha_{\mathrm{R}}}{\mathrm{N}}\left(\frac{\mathrm{h}}{\mathrm{T}_{\mathrm{R}}}\right)^{2} \mathrm{~W}^{2}\left(\frac{\mathrm{K}_{\mathrm{R}}}{\mathrm{K}_{1}+\mathrm{K}_{\mathrm{R}}}\right)^{2} \mathrm{a}_{\mathrm{y}}^{2}\right]^{2} \mathrm{~g}}
$$ 
Note that Equation ( $B-5)$ is the classical critical velocity expression except for the additional partial derivative terms denoting dependence of $\ell_{e}^{\prime}$ and $K^{\prime}$ (and hence $U_{c}$ ) upon lateral acceleration. Recall that the dependence of $\ell_{e}^{\prime}$ and $K^{\prime}$ on lateral acceleration is directly related to the side-to-side load transfer assumption and variation of tire cornering stiffness with vertical load discussed in Appendix A. 

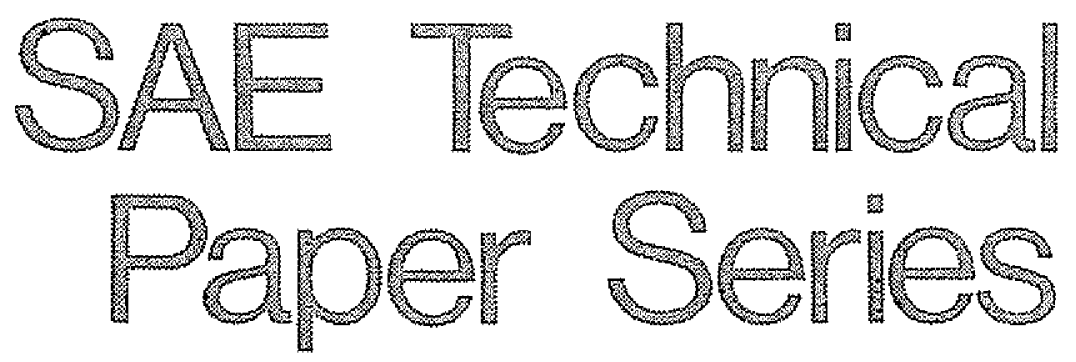

821260

\section{A Computer-Based Study of the Yaw/Roll Stability of Heavy Trucks Characterized by High Centers of Gravity}

Charles C. MacAdam

The University of Michigan Transportation Research Institute 